\title{
Journalof the American Chemical Society
}

Subscriber access provided by NATIONAL TAIWAN UNIV

\section{Article}

\author{
Poly-I-Lysine Templated Silicas: Using Polypeptide \\ Secondary Structure to Control Oxide Pore Architectures \\ Kristy M. Hawkins, Steven S.-S. Wang, David M. Ford, and Daniel F. Shantz \\ J. Am. Chem. Soc., 2004, 126 (29), 9112-9119 • DOI: 10.1021/ja049936o
}

Downloaded from http://pubs.acs.org on November 26, 2008

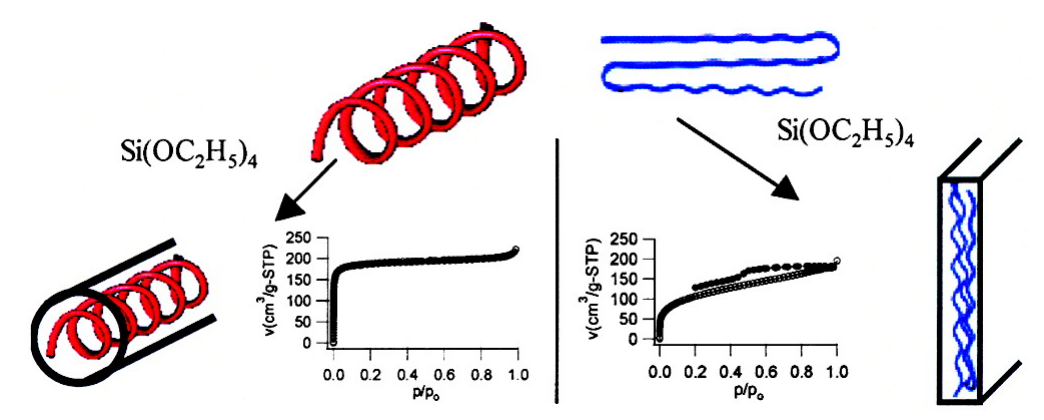

\section{More About This Article}

Additional resources and features associated with this article are available within the HTML version:

- Supporting Information

- Links to the 10 articles that cite this article, as of the time of this article download

- Access to high resolution figures

- Links to articles and content related to this article

- Copyright permission to reproduce figures and/or text from this article

\section{View the Full Text HTML}

\section{ACS Publications}


Published on Web 07/02/2004

\title{
Poly-L-Lysine Templated Silicas: Using Polypeptide Secondary Structure to Control Oxide Pore Architectures
}

\author{
Kristy M. Hawkins, ${ }^{\dagger}$ Steven S.-S. Wang, ${ }^{\ddagger}$ David M. Ford, and Daniel F. Shantz ${ }^{\star}$ \\ Contribution from the Department of Chemical Engineering, Texas A\&M University, \\ College Station, Texas 77843 \\ Received January 5, 2004; E-mail: shantz@che.tamu.edu
}

\begin{abstract}
Utilizing polypeptide secondary structure as a means for controlling oxide pore architectures is explored. Poly-L-lysine is used as a model polypeptide as its folding behavior is well understood and compatible with the sol-gel chemistry of silica. Here, we show that silicas synthesized with poly-L-lysine in a $\alpha$-helix conformation possess cylindrical pores that are approximately $1.5 \mathrm{~nm}$ in size, whereas silicas synthesized with poly-L-lysine in a $\beta$-sheet conformation possess larger pores, the size of which are a function of the poly-L-lysine concentration, or in other words the size of the aggregate. In both cases, highly porous materials are obtained. In-situ circular dichroism measurements of the synthesis mixtures show that the poly-L-lysine secondary structure is not perturbed during synthesis. Infrared spectroscopy of the as-synthesized materials is consistent with the poly-L-lysine retaining its secondary structure. Grand canonical Monte Carlo simulations were also performed to validate the interpretation of the experimental adsorption results. The experimental isotherms are consistent with simulated isotherms of cylindrical pores 1.3-1.7 $\mathrm{nm}$ in size, in good agreement with expected values. Our results suggest a new avenue for synthesizing porous oxides with highly tuneable pore sizes and shapes under mild conditions.
\end{abstract}

\section{Introduction}

The synthesis of porous inorganic oxides is an active, technologically important, but also relatively mature field. A variety of methodologies have been employed to make interesting porous materials ranging from hydrothermal syntheses in the presence of an organic moiety (e.g., zeolites) ${ }^{1-4}$ to selfassembling entities such as surfactants and block copolymers (e.g., M41S/SBA-15) ${ }^{5,6}$ to organic gelators. ${ }^{7,8}$ Given the enormous interest in developing the ability to control structure and function over multiple length scales this is an area that will undoubtedly continue to be actively pursued. Such materials will find applications in a range of areas including catalysis, separations, and sensing.

In this vein, polypeptides have recently drawn considerable attention for assembling inorganic materials. ${ }^{9-19}$ These inves-

$\dagger$ Current Address: Department of Chemical Engineering, California Institute of Technology, Mail Code 210-41 1200 E. California Blvd., Pasadena, CA 91125.

$\doteqdot$ Current Address: Department of Chemical Engineering, National Taiwan University, No 1, Sec 4, Roosevelt Rd, Taipei, Taiwan 106.

(1) Barrer, R. M. Hydrothermal Chemistry of Zeolites; Academic Press: London, 1982

(2) Davis, M. E.; Lobo, R. F. Chem. Mater. 1992, 4, 756-768.

(3) Davis, M. E. Nature 2002, 417, 813-821.

(4) Schueth, F.; Schmidt, W. Adv. Mater. 2002, 14, 629-638

(5) Kresge, C. T.; Leonowicz, M. E.; Roth, W. J.; Vartuli, J. C.; Beck, J. S. Nature 1992, 359, 710-712.

(6) Zhao, D. Y.; Feng, J. L.; Huo, Q. S.; Melosh, N.; Fredrickson, G. H.; Chmelka, B. F.; Stucky, G. D. Science 1998, 279, 448-452.

(7) Jung, J. H.; Ono, Y.; Hanabusa, K.; Shinkai, S. J. Am. Chem. Soc. 2000, $122,5008-5009$

(8) Jung, J. H.; Shinkai, S.; Shimizu, T. Chem. Mater. 2003, 15, 2141-2145.

(9) Cha, J. N.; Shimizu, K.; Zhou, Y.; Christiansen, S. C.; Chmelka, B. F.; Stucky, G. D.; Morse, D. E. Proc. Natl. Acad. Sci. U.S.A. 1999, 96, 361365 .

9112 — J. AM. CHEM. SOC. 2004, 126, 9112-9119 tigations have focused on three specific, and somewhat related, issues: the first is manipulating oxide morphology, the second is controlling crystal growth, and the third, the source of inspiration for the first two, is developing a "biomimetic" approach to inorganic materials synthesis. With regard to the last point, materials such as silica diatoms and nacre are held out as the ultimate examples of the complex structures nature can assemble at ambient conditions. In many regards, these works have energized the field of inorganic materials chemistry and have been summarized in several excellent reviews. ${ }^{18,20-22}$ Here, however, we use a different property of polypeptides to achieve rational control over material properties, namely secondary structure. It is well-known that polypeptides and proteins adopt a variety of conformations, most prominently $\alpha$-helices and $\beta$-sheets, and that it is the folded state of the protein that induces its biological function. ${ }^{23}$ In this investiga-

(10) Cha, J. N.; Stucky, G. D.; Morse, D. E.; Deming, T. J. Nature 2000, 403, 289-292.

(11) Coradin, T.; Durupthy, O.; Livage, J. Langmuir 2002, 18, 2331-2336.

(12) Coradin, T.; Livage, J. Coll. Surf. B: Biointerfaces 2001, 21, 329-336.

(13) Kroeger, N.; Deutzmann, R.; Sumper, M. Science 1999, 286, 1129-1132.

(14) Naik, R. R.; Whitlock, P. W.; Rodriguez, F.; Brott, L. L.; Glawe, D. D.; Clarson, S. J.; Stone, M. O. Chem. Commun. 2003, 238-239.

(15) Noll, F.; Sumper, M.; Hampp, N. NanoLett. 2002, 2, 91-95.

(16) Reches, M.; Gazit, E. Science 2003, 300, 625-627.

(17) Sumper, M. Science 2002, 295, 2430-2433.

(18) van Bommel, K. J. C.; Friggeri, A.; Shinkai, S. Angew. Chem., Int. Ed. 2003, 42, 980-999.

(19) Wong, M. S.; Cha, J. N.; Choi, K. S.; Deming, T. J.; Stucky, G. D. Nano Lett. 2002, 2, 583-587.

(20) Zaremba, C. M.; Stucky, G. D. Curr. Opin. Sol. State. Mater. Sci. 1996, 1, $425-429$.

(21) Estroff, L. A.; Hamilton, A. D. Chem. Mater. 2001, 13, 3227-3235.

(22) Coradin, T.; Lopez, P. J. ChemBioChem 2003, 4, 251-259.

(23) Branden, C.; Tooze, J. Introduction to Protein Structure; Garland: New York, 1999.

10.1021/ja049936o CCC: $\$ 27.50$ @ 2004 American Chemical Society 
tion, we wish to determine if polypeptides in different conformations can be used as templates for fabricating porous oxides, wherein the size and shape of the pores are determined by the secondary structure of the polypeptide. Given that polypeptides have chemical functionality on the molecular level and possess structure on length scales ranging from 1 to $100 \mathrm{~nm}$ that can be manipulated and controlled simultaneously, ${ }^{23,24}$ we believe that the ability to tune porosity using secondary structure could open new possibilities in materials synthesis. The ability to tune porosity through secondary structure could subsequently be coupled with other properties of biological macromolecules or mimics thereof to fabricate complex porous oxides possessing multiple structural features at multiple length scales (e.g., hierarchical porosity, controlling morphology and porosity simultaneously, etc.).

However, to realize such ambitious goals we must take the first step, the topic described here, which is demonstrating the ability to use polypeptide secondary structure as means to design the porosity of an oxide made in its presence. Here, using a simple polypeptide, poly-L-lysine, we show that secondary structure can be used to rationally design the porosity of silica made in its presence. Our work shows that silicas made using poly-L-lysine in an $\alpha$-helix possess highly uniform pores approximately $1.5 \mathrm{~nm}$ in diameter. This is consistent with smallangle X-ray scattering measurements that show helical poly-Llysine in solution to be cylindrical with a diameter of approximately $1.5 \mathrm{~nm}$. By contrast silicas synthesized with poly-L-lysine in a $\beta$-sheet conformation possess larger pores, the size of which are a function of the poly-L-lysine concentration, or in other words the size of the aggregate. In both cases, highly porous materials are obtained $\left(>0.2 \mathrm{~cm}^{3} / \mathrm{g}\right)$. In-situ circular dichroism measurements of the synthesis mixtures show that the poly-Llysine secondary structure is not perturbed during synthesis. Infrared spectroscopy of as-synthesized polypeptide-silica composites is consistent with the poly-L-lysine occluded in the material being in a folded state. A complication in this work is that the materials formed, while possessing highly uniform pores, do not possess long-range structural ordering and hence the pore architecture is not amenable to elucidation by microscopy and diffraction. With this in mind, we turned to grand canonical Monte Carlo simulations to validate the interpretation of the experimental isotherms. The experimental isotherms are consistent with simulated isotherms of cylindrical pores between 1.3 and $1.7 \mathrm{~nm}$ in size, in good agreement with expected values. This approach is unique in that while many synthetic schemes utilize hydrogen-bonding interactions to direct the assembly of a porous oxide, here we use an isolated macromolecular structure versus an aggregate of molecules such as surfactant micelles. Our results suggest a new avenue for synthesizing porous oxides with highly tunable pore sizes and shapes under mild conditions and are proof of concept that the secondary structure of a polypeptide chain can be used to rationally manipulate the porosity of silica.

\section{Experimental Methods}

Poly-L-lysine $\cdot \mathrm{HBr}$ (PLL) was used as received from Sigma-Aldrich. Tetraethyl orthosilicate (TEOS) was used as received from Fluka. $1 \mathrm{~N}$ sodium hydroxide solutions were made using sodium hydroxide $(85 \%+$,

(24) Creighton, T. E. Proteins: Structures and Molecular Principles; W. H. Freeman: New York, 1993
ACS Reagent) from EM Science. Unless noted specifically in the text, the PLL molecular weight was approximately 20000 with a polydispersity index of 1.3. The PLL solution $\mathrm{pH}$ was adjusted to the desired value by dropwise addition of $1.0 \mathrm{~N} \mathrm{NaOH}$. Silicas were synthesized in the $\mathrm{pH}$ range of 9-11.2. The amount of PLL used in synthesis is denoted in the figures, but was typically $0.5 \mathrm{mg}$ PLL/ $1 \mathrm{~mL}$ water. To form the poly-L-lysine/silica composites TEOS, typically at a concentration of 0.1 mol TEOS/1 L PLL solution, was added to the PLL solution while mixing. To keep the $\mathrm{pH}$ constant $( \pm 0.05)$ during silica polymerization $1.0 \mathrm{~N} \mathrm{NaOH}$ was added dropwise as needed. In all cases, within $2 \mathrm{~h}$ the $\mathrm{pH}$ no longer changed indicating the reaction of the TEOS was essentially complete. The mixtures were usually allowed to stand overnight while mixing, though the final material properties were insensitive to aging time. The solids were recovered by filtration and washed with copious quantities of deionized water. The poly-Llysine was removed from the sample by heating at $550{ }^{\circ} \mathrm{C}$ in air for 8 h.

Nitrogen and argon adsorption measurements were performed using a Micromeritics 2010 ASAP instrument at $77 \mathrm{~K}$. Surface areas and pore volumes were determined using nitrogen and argon adsorption isotherm data using the $\alpha_{\mathrm{s}}$-method, ${ }^{25}$ and mesopore size distributions were calculated using the $\mathrm{BJH}$ method ${ }^{26}$ with a modified form for the statistical film thickness. ${ }^{27}$ Data used for $\alpha_{\mathrm{s}}$-analysis were obtained from the literature. ${ }^{28}$ Micropore size calculations were performed using argon and nitrogen adsorption isotherms with the Horvath-Kawazoe method assuming a cylindrical pore geometry ${ }^{29,30}$ at $77 \mathrm{~K}$, and also through comparisons of simulated argon adsorption isotherms determined using grand canonical Monte Carlo (GCMC) simulations. Simulations of argon adsorption in cylindrical pores at $77 \mathrm{~K}$ were carried out using the GCMC algorithm described by Frenkel and Smit. ${ }^{31}$ The potential model employed was identical to that used by Vishnyakov and Neimark for MCM-41 materials; ${ }^{32}$ it included Lennard-Jones (LJ) interactions between the argon molecules and a smeared LJ interaction between the argon molecules and the oxygen atoms of the silica. The points on the adsorption isotherms were obtained in sequential fashion. Three million GCMC cycles were run at each point, with the results of the first 1.5 million cycles discarded as equilibration. In addition, the first three points of an isotherm sequence were always discarded. The isotherms are reported in dimensionless units of absolute adsorbed density, $\rho \sigma^{3}$, where $\rho$ is the number of argon molecules per unit pore volume and $\sigma$ is the LJ length parameter for argon. For the adsorption conditions and pore sizes reported here, the difference between the absolute and Gibbs excess adsorbed densities is negligible $(<1 \%)$.

Circular dichroism measurements were performed with a AVIV Stopped Flow Circular Dichroism Spectrometer Model 202SF. Dynamic light scattering measurements were performed on a Brookhaven ZetaPals instrument. Powder X-ray diffraction (XRD) was performed on a Bruker-AXS D8 powder diffractometer using $\mathrm{CuK} \alpha$ radiation. Samples were analyzed over a range of 0.1 to $15^{\circ} 2 \theta$ using a step scan mode with a step size of $0.02^{\circ}$ and a step rate of $10 \mathrm{~s} / \mathrm{step}$. Peak intensities and $2 \theta$ values were determined using the Bruker package EVA. Infrared spectroscopy was performed on a Thermo Nicolet Nexus 670 FTIR. Background spectra were collected after $30 \mathrm{~min}$ of evacuation. A powder mixture of mass ratio 0.01 sample: 0.99 potassium bromide (Aldrich) was pelletized and analyzed after $30 \mathrm{~min}$ of evacuation. 128 scans were acquired per spectrum. TGA data was collected on a TG 209C Iris from Netzsch Instruments. Samples were

(25) Rouquerol, F.; Roquerol, J.; Sing, K. Adsorption by Powders and Porous Solids; Academic: San Diego, 1999.

(26) Barrett, E. P.; Joyner, L. G.; Halenda, P. P. J. Am. Chem. Soc. 1951, 73 , 373-380.

(27) Kruk, M.; Jaroniec, M.; Sayari, A. Langmuir 1997, 13, 6267-6273.

(28) Jaroniec, M.; Kruk, M.; Olivier, J. P. Langmuir 1999, 15, 5410-5413.

(29) Saito, A.; Foley, H. C. AIChE J. 1991, 37, 429-436.

(30) Saito, A.; Foley, H. C. Micropor. Mater. 1995, 3, 531-542.

(31) Frenkel, D.; Smit, B. Understanding Molecular Simulation: From Algorithms to Applications; Academic Press: San Diego, 2002.

(32) Vishnyakov, A.; Neimark, A. V. J. Phys. Chem. B 2001, 105, 7009-7020. 


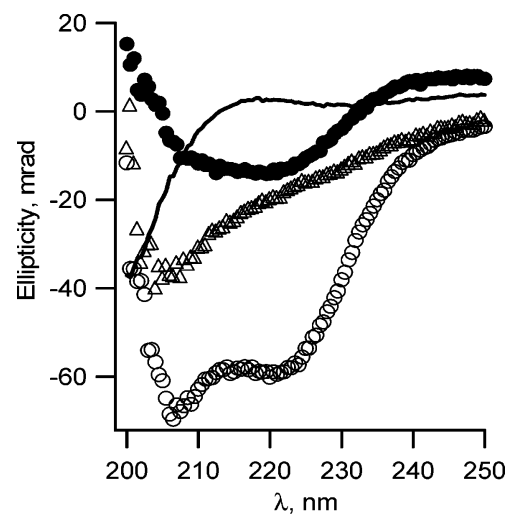

Figure 1. Circular dichroism of $20 \mathrm{~K}$ MW poly-L-lysine $\cdot \mathrm{HBr}(0.05 \mathrm{mg} /$ $\mathrm{mL}$ ) under various conditions (open circles, $\mathrm{pH} 11.2$, closed circles, $\mathrm{pH}$ 11.2 and heated, solid line $\mathrm{pH}$ 6) and $3800 \mathrm{MW}$ poly-L-lysine $\cdot \mathrm{HBr}(0.05$ $\mathrm{mg} / \mathrm{mL}$ ) (open triangles).

heated from room temperature to $650{ }^{\circ} \mathrm{C}$ at a rate of $5{ }^{\circ} \mathrm{C} / \mathrm{min}$. Transmission electron microscopy was performed on a JEOL 2010 microscope with $\mathrm{a} \mathrm{LaB}_{6}$ filament and an excitation voltage of $200 \mathrm{kV}$. The samples were mortar and pestled and then dispersed in ethanol (100\%, Aldrich) and placed on a 400-mesh copper grid. Small-angle $\mathrm{X}$-ray scattering experiments were performed on Bruker NanoSTAR system employing a Nonius FR591 rotating anode (Cu target, operated at $45 \mathrm{kV}$ and $90 \mathrm{~mA}$ ) and cross-coupled Göbel mirrors. The scattering data was recorded on a two-dimensional multiwire Hi-STAR detector $(1024 \times 1024$ pixels $)$ under vacuum at a sample-to-detector length of $64 \mathrm{~cm}$, corresponding to a $q$ range of approximately $0.01 \sim 0.3 \AA^{-1}(q$ $=4 \pi \sin (\theta) / \lambda, \theta$ is half of the scattering angle and $\lambda$ is the wavelength of the incident beam). Water was used as an absolute standard.

\section{Results and Discussion}

Figure 1 shows representative circular dichroism (CD) spectra of $20 \mathrm{~K} \mathrm{MW}$ poly-L-lysine (PLL) in various conformations as well as low MW (3800) PLL at pH = $11.2( \pm 0.05)$. Consistent with previous work ${ }^{33,34}$ circular dichroism shows PLL at $\mathrm{pH}$ $=11.2( \pm 0.05)$ is predominantly in the $\alpha$-helix conformation. As can be seen there are two well-defined minima at 206 and $220 \mathrm{~nm}$, attributable to the $\alpha$-helix. Heating this solution at 328 $\mathrm{K}$ for $30 \mathrm{~min}$ led to $\beta$-sheet formation, as evidenced by the replacement of the two minima at 206 and $220 \mathrm{~nm}$ with a broad minimum centered at $210 \mathrm{~nm}$. By contrast, solutions measured at pH 6 exhibit a minimum at $200 \mathrm{~nm}$ and a positive ellipticity at $220 \mathrm{~nm}$, indicative of a random coil conformation. The 3800 MW sample, while not exhibiting the clear double-minima observed for the $20 \mathrm{~K} \mathrm{MW}$ PLL, nevertheless possesses a small amount of helicity. This conclusion is based on the lack of positive ellipticity at $220 \mathrm{~nm}$ and that the signal minimum for this sample is at $205 \mathrm{~nm}$, not $200 \mathrm{~nm}$ as is observed for a random coil. This is consistent with previous work that has shown for lysine oligomers that the first sign of helicity can be detected for 12 -mers. ${ }^{35}$ The $3800 \mathrm{MW}$ polymer should on average contain 19 residues. Given the polydispersity of the PLL and variance in molecular weight from batch to batch, we did not feel quantitatively analyzing the spectra was warranted. However, it is important to note that the spectra are reproducible and consistent with previous reports in the literature. We have also performed $\mathrm{CD}$ measurements on PLL solutions at $\mathrm{pH}=11.2$

(33) Davidson, B.; Fasman, G. D. Biochemistry 1967, 6, 1616-1629.

(34) Greenfield, N.; Fasman, G. D. Biochemistry 1969, 8, 4108-4116.

(35) Yaron, A.; Katchalski, E.; Berger, A.; Fasman, G. D.; Sober, H. A. Biopolymers 1971, 10, 1107-1120.

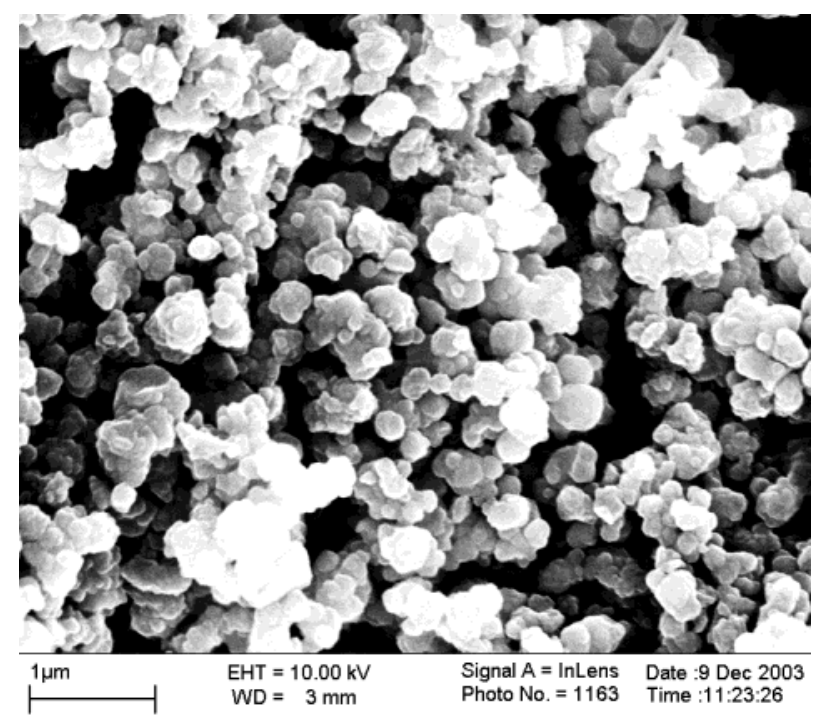

Figure 2. Field emission scanning electron micrograph of silica made in the presence of poly-L-lysine $\cdot \mathrm{HBr}(0.5 \mathrm{mg} / \mathrm{mL})$ at $\mathrm{pH}=11.2$ Scale bar is $1 \mu \mathrm{m}$.

containing $0.5 \mathrm{M}$ ethanol; these are essentially identical to the results shown in Figure 1 and indicate the PLL does not unfold in the presence of $0.5 \mathrm{M}$ ethanol. Small-angle X-ray scattering (SAXS, Supporting Information) of a solution containing $5 \mathrm{mg} /$ $\mathrm{mL}$ of PLL at $\mathrm{pH}=11.2$ shows the PLL scattering matches that of cylinders of dimension $18 \times 110 \AA^{2}$, consistent with the expected values for PLL in a helical conformation (diameter $17 \AA$ from molecular modeling, $125 \AA$ in length based on 1.5 $\AA /$ residue pitch in helix). Figure 2 shows a FE-SEM image of a silica made in the presence of PLL at $\mathrm{pH}=11.2$ (helical). As can be seen the particles are on average $200 \mathrm{~nm}$ in size. This is consistent with previous work. ${ }^{11}$ This result is mentioned here as given the relatively small size of the particles one can anticipate that the materials will have an appreciable external surface area. This will be described in more detail below.

Figure 3 shows the nitrogen adsorption isotherms for samples made with PLL $(0.5 \mathrm{mg} / \mathrm{mL})$ in an $\alpha$-helix and $\beta$-sheet conformation at $\mathrm{pH}=11.2$. For clarity, these samples will hereafter be referred to as AHTS ( $\alpha$-helical templated silica) and BSTS ( $\beta$-sheet templated silica). The materials have substantially different adsorptive properties as can be seen on inspection of the isotherms. The two most notable differences are the amount of nitrogen adsorbed between $0.1<p / p_{\mathrm{o}}<0.8$ and that the BSTS exhibits adsorption/desorption hysteresis. The AHTS isotherm is a Type I isotherm, indicative of a material possessing micropores $(<2 \mathrm{~nm})$, whereas the BSTS has a sizable fraction of pores larger than $2 \mathrm{~nm}$. That the BSTS isotherm does not close at a $p / p_{\mathrm{o}} \approx 0.42$ is consistent with the pore structure being highly interconnected and slit-shaped. ${ }^{25}$ Adsorption measurements performed on silicas with the poly-L-lysine occluded in the pores (i.e. before calcination) indicate they do not possess any microporosity (not shown). It is also important to note that mixtures with the same TEOS concentration buffered to the same $\mathrm{pH}$ (11.2) without poly-L-lysine do not form silica particles larger than $100 \mathrm{~nm}$ over the time period of several days, but rather remain as optically clear solutions. This is evidence that the PLL acts as a template for material formation. This is due to hydrogen-bonding interactions between the electrically neutral $N_{\epsilon}-$ amine groups and the negatively 

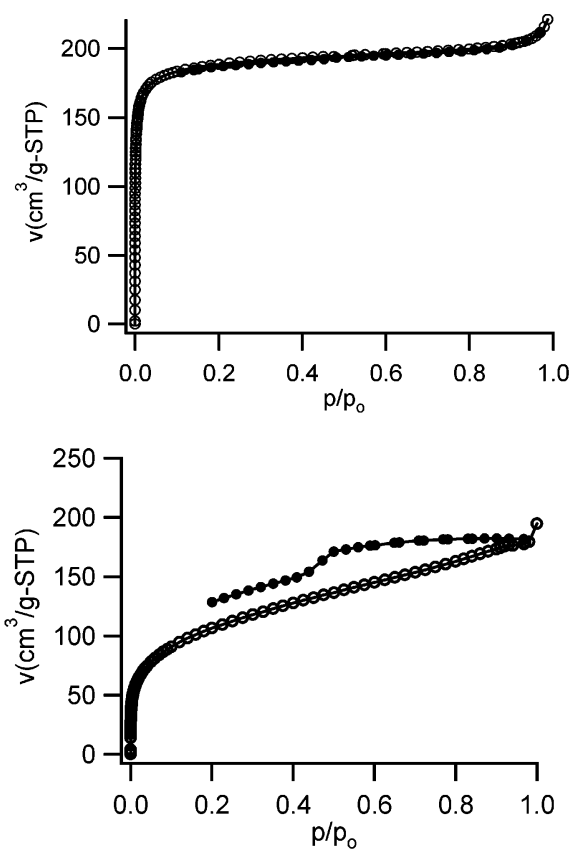

Figure 3. Nitrogen adsorption isotherms at $77 \mathrm{~K}$ of silicas made at $\mathrm{pH}=$ 11.2 using $0.5 \mathrm{mg} / \mathrm{mL}$ poly-L-lysine $\cdot \mathrm{HBr}$ in an $\alpha$-helical (top) and $\beta$-sheet conformation (bottom). Open and closed circles are the adsorption and desorption isotherms, respectively.

charged silicates in solution. At the $\mathrm{pH}$ used for synthesis (11.2), the PLL side chains should be neutral as this is well above the $\mathrm{p} K_{\mathrm{A}}$ of the side chains $(9.5-10),{ }^{36}$ and most if not all of the silanol ( $\equiv \mathrm{Si}-\mathrm{OH})$ groups should be deprotonated. ${ }^{37}$ Thermogravimetric analysis shows that the as-synthesized materials typically contain between 38 and 40 wt \% PLL. The yield of silica (based on the amount of TEOS added) is typically $20 \%$. This low yield is qualitatively consistent with a specific interaction leading to material formation. The isotherms, coupled with TGA and IR (see below) results that clearly show the PLL is occluded in the pores of the resultant silica, indicate that the materials made with PLL in different secondary structures possess at least qualitatively different pore architectures, the nature of which are quantified below.

The pore volumes and surface areas were determined using the $\alpha_{\mathrm{s}}$ analysis method, where the adsorptive properties of the sample are compared to that of a nonporous reference material. ${ }^{25,27,28}$ This analytical method has the advantage that it is independent of physical models and the only assumption made is that the surface of the material is chemically similar to that of a macroporous reference sample ${ }^{28}$ which is true in our case. Figure 4 shows the $\alpha_{s}$ plots of the isotherms and a tangent line at an $\alpha_{\mathrm{s}}$ value of 0.7 , typically taken to be the value where micropore filling is complete. From these plots we determine that the AHTS and BSTS have pore volumes of $0.26 \mathrm{~cm}^{3} / \mathrm{g}$ and $0.03 \mathrm{~cm}^{3} / \mathrm{g}$, respectively below $\alpha_{\mathrm{s}}$ of $0.7\left(p / p_{\mathrm{o}} \approx 0.12\right)$. This is consistent with the ASTS possessing solely micropores $(<2 \mathrm{~nm})$ whereas the BSTS has larger pores with a broader pore size distribution. Taking tangent lines at an $\alpha_{\mathrm{s}}$ value of 2.0 shows that the AHTS and BSTS have similar total pore volumes of 0.28 and $0.26 \mathrm{~cm}^{3} / \mathrm{g}$ respectively (Supporting

(36) Barrett, G. C. Amino Acids and Peptides. 1998, Cambridge University Press: Cambridge.

(37) Iler, R. K. The Chemistry of Silica: Solubility, Polymerization, Colloid and Surface Properties, and Biochemistry; Wiley: New York, 1979.
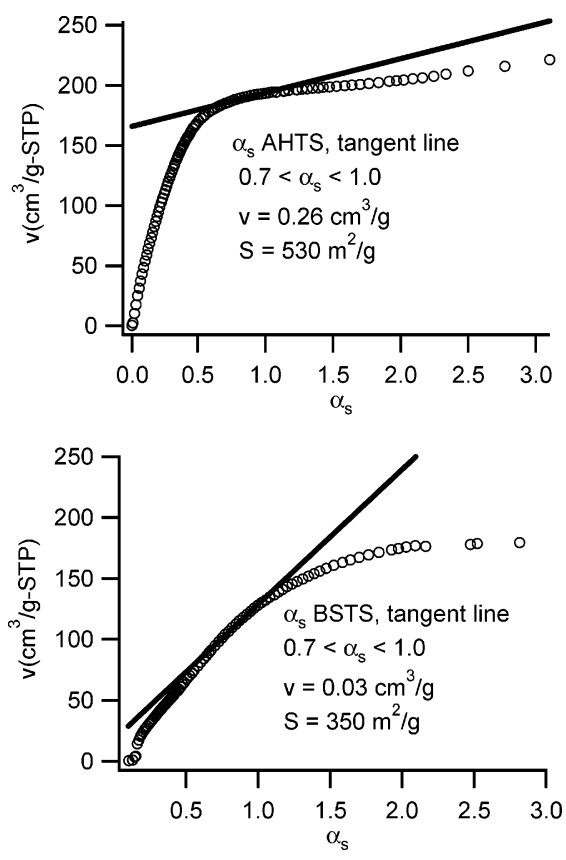

Figure 4. $\alpha_{\mathrm{s}}$-plots of AHTS and BSTS with tangent lines at $0.7<\alpha_{\mathrm{s}}<$ 1.0. Isotherms analyzed are those shown in Figure 3.

Information). The surface areas of AHTS and BSTS determined using the $\alpha_{\mathrm{s}}$ method are 530 and $350 \mathrm{~m}^{2} / \mathrm{g}$, respectively.

$\mathrm{BJH}$ analysis using a modification described by Kruk and co-workers $^{26,27}$ was used to estimate the pore size of any mesopores present. Their work has shown that capillary condensation occurs in $2 \mathrm{~nm}$ diameter pores at a $p / p_{\mathrm{o}}$ value of approximately 0.12 . As such we conclude that only a very small amount $\left(0.02 \mathrm{~cm}^{3} / \mathrm{g}\right)$ of the total pore volume of AHTS is due to pores larger than $2 \mathrm{~nm}$. However, the $\mathrm{BJH}$ method is derived assuming capillary condensation, and it is still an unresolved issue of whether this description is adequate for pores less than $4 \mathrm{~nm}$ in size. ${ }^{25}$ As such, its applicability to the AHTS is questionable at best. However, it is important to point out that in any event the contribution of any mesopores to the porosity of AHTS is very small $(<5 \%)$ and the small volume adsorbed at higher pressures could also be accounted for by multilayer adsorption on the outer surface of the particles, which are generally $200 \mathrm{~nm}$ in size. By contrast, the majority of the pore volume $\left(0.24 \mathrm{~cm}^{3} / \mathrm{g}\right)$ observed for BSTS is due to pores larger than $2 \mathrm{~nm}$ and the BJH analysis for BSTS shows that material has a broad range $(2-8 \mathrm{~nm})$ of pore sizes. We believe that the broad pore size distribution observed for the BSTS is due to the fact that there is both intra- and interstrand $\beta$-sheet formation. To probe this, we synthesized a sample of BSTS using only $0.05 \mathrm{mg} / \mathrm{mL}$ of PLL, conditions where intrastrand $\beta$-sheet formation dominates. ${ }^{33}$ This material has a much narrower pore size distribution $\left(0.07 \mathrm{~cm}^{3} / \mathrm{g}\right.$ of pores $\left.>2 \mathrm{~nm}\right)$, the pores are smaller, and possesses a surface area and pore volume of 415 $\mathrm{m}^{2} / \mathrm{g}$ and $0.19 \mathrm{~cm}^{3} / \mathrm{g}$, respectively (Supporting Information). This result indicates that the pore size distribution and pore volume for the BSTS materials are a function of the concentration of the PLL in solution. This is not observed for the AHTS materials, as the isotherms for samples made with a wide range of PLL concentrations $(0.5-40 \mathrm{mg} / \mathrm{mL})$ are essentially identical (see Supporting Information). The insensitivity of the material properties to polypeptide concentration is consistent with the 
Table 1. Nitrogen Adsorption Data of Poly-L-Lysine Templated Silicas $(\mathrm{pH} 11.2,0.5 \mathrm{mg} / \mathrm{mL}$ Poly-L-lysine $\cdot \mathrm{HBr}$, [TEOS] $=0.1 \mathrm{M})$

\begin{tabular}{lcccc}
\hline & AHTS & $\begin{array}{c}\text { BSTS } 0.5 \\
\mathrm{mg} / \mathrm{mL}\end{array}$ & $\begin{array}{c}\text { BSTS 0.05 } \\
\mathrm{mg} / \mathrm{mL}\end{array}$ & $\begin{array}{c}\text { low-MW } \\
\text { poly-lysine } \\
\text { (coil) }\end{array}$ \\
\hline $\begin{array}{l}\text { micropore } \\
\text { volume }\left(\mathrm{cm}^{3} / \mathrm{g}\right)\end{array}$ & 0.26 & 0.03 & 0.12 & $<0.001$ \\
$\begin{array}{l}\text { total pore } \\
\text { volume }\left(\mathrm{cm}^{3} / \mathrm{g}\right)\end{array}$ & 0.28 & 0.26 & 0.19 & 0.02 \\
$\begin{array}{l}\text { surface } a r e a \\
\left(\mathrm{~m}^{2} / \mathrm{g}\right)\end{array}$ & 530 & 350 & 415 & 20 \\
pore size $(\mathrm{nm})$ & $1.4^{\mathrm{a}}$ & $2-8^{\mathrm{b}}$ & $1.5-4^{\mathrm{b}}$ & $\mathrm{N} / \mathrm{A}$ \\
\hline
\end{tabular}

${ }^{a}$ Based on HK analysis. ${ }^{b}$ Based on BJH analysis.

idea that individual PLL chains are responsible for material formation (i.e., a templating effect).

We also studied different syntheses using PLL that would adopt a random coil conformation as a comparison to the samples discussed above. Syntheses at $\mathrm{pH} 9$ were initially investigated and the isotherms possess moderate differences from those of samples made at $\mathrm{pH}$ 11.2. However, there are two important differences which preclude a meaningful comparison of this sample to AHTS to ascertain the secondary structure effects: (1) the kinetics of silicate hydrolysis, condensation, polymerization are dramatically different at $\mathrm{pH} 9$ than at $\mathrm{pH} 11.2,{ }^{37}$ and (2) at $\mathrm{pH} 9$ most of the side chains of the PLL will be charged, leading to a highly extended conformation. We also performed syntheses with a random copolymer of polyDL-lysine. Although this material appears different from the PLL templated samples there are again two complications: (1) the stereochemistry is not the same, and (2) CD of the batch of poly-DL-lysine used (not shown) indicated that the polypeptide was not truly a random coil (positive ellipticity at $220 \mathrm{~nm}$ was not observed). As such we decided the best comparison would be to use a low MW PLL (MW 3800) that does not exhibit substantial helical content at any $\mathrm{pH}$. This would allow us to study a PLL that has the same stereochemistry as our higher molecular weight PLL that has a relatively low helical content at $\mathrm{pH} 11.2$, enabling us to keep the $\mathrm{pH}$ constant for comparison to the AHTS and BSTS syntheses. The material made from this synthesis had a very low surface area $\left(20 \mathrm{~m}^{2} / \mathrm{g}\right)$ and total pore volume $\left(0.02 \mathrm{~cm}^{3} / \mathrm{g}\right)$. Although some of this could be attributable to possible molecular weight effects, previous works have clearly shown that lysine can effect the precipitation of silica under alkaline conditions. ${ }^{11,12}$ As such, we believe that the difference between this material and the AHTS materials must at least be in part due to the fact the low molecular weight PLL has a much lower helical content, and subsequently we find these materials do not possess comparable porosity. The adsorption results are summarized in Table 1. The pore-size distributions obtained by Horvath Kawazoe analysis for AHTS are included in the Supporting Information for completeness. Given that this method is well-known to be unreliable for determining the pore sizes of large-pored microporous materials, ${ }^{30,38}$ we believe it is necessary to use another technique to validate our interpretation of the adsorption results. We have chosen grand canonical Monte Carlo simulations of Argon adsorption for that purpose (see below).

It would clearly be advantageous for the purpose of characterization to synthesize silicas wherein the pores possess long-

(38) Davis, M. E.; Montes, C.; Hathaway, P. E.; Arhancet, J. P.; Hasha, D. L.; Garces, J. M. J. Am. Chem. Soc. 1989, 111, 3919-3924.

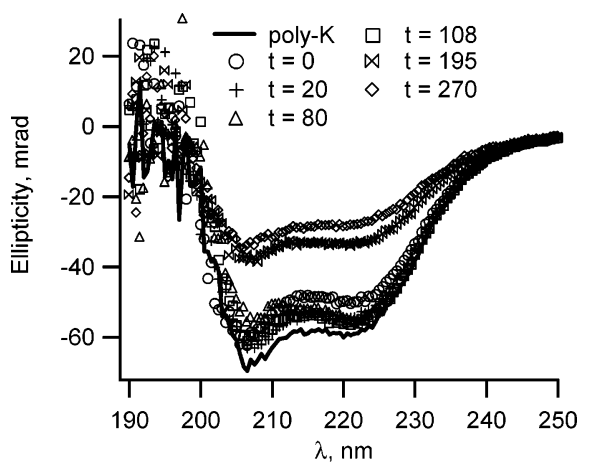

Figure 5. In situ circular dichroism data for AHTS solutions. The time denoted in the figure is in minutes.

range ordering, and hence are amenable to analysis using diffraction and microscopy. This prompted us to synthesize a series of AHTS samples with varying PLL contents (0.5-40 $\mathrm{mg} / \mathrm{mL}$ ) as described above. In all cases, however, the powder $\mathrm{X}$-ray diffraction patterns looked similar; a broad feature at $4^{\circ}$ $2 \theta$ (Supporting Information). This corresponds to a $d$-spacing of $25 \AA$. However the materials do not possess long-range order based on the diffraction results; this conclusion was also verified using TEM (Supporting Information). As such the discussion that follows will focus on two issues to validate our hypothesis that pore architectures formed are a direct result of the secondary structure of poly-L-lysine: (1) is the secondary structure perturbed during silica formation? and (2) are the isotherms obtained from GCMC simulations consistent with our experimental results?

Figure 5 shows in-situ circular dichroism measurements of a mixture that leads to the formation of AHTS. As can be seen, the CD spectra for reaction times below $195 \mathrm{~min}$ are essentially identical to the spectrum of the native PLL solution, the only difference being a slight decrease in the intensity of the two minima. This could be due to either a slight decrease in the helical content due to the presence of ethanol liberated in the hydrolysis of the TEOS, or a dilution effect of the PLL (the solutions are $0.1 \mathrm{~N}$ in TEOS). The CD spectra from $t=0 \mathrm{~min}$ (TEOS addition) to $t=108 \mathrm{~min}$ are essentially identical, indicating that the secondary structure of the PLL does not appreciably change during the material formation. The spectra for 195 and 270 min show a decrease in intensity of the signal, but still clearly display the double minima indicative of the presence of helical PLL. By these reaction times, the solution has changed from optically transparent solution to a semi-opaque suspension of silica particles in water. As such, one would expect a decrease in the overall signal intensity given the path length (i.e., cuvette size) is the same for all spectra shown in Figure 6. Dynamic light scattering on a mixture of similar composition (not shown) indicates the presence of particles larger than $100 \mathrm{~nm}$ after $30 \mathrm{~min}$. The CD results indicate the secondary structure of the PLL in solution is not perturbed by the polymerization of the silica. Figure 6 shows the in-situ circular dichroism of silicas made in the presence of $3800 \mathrm{MW}$ PLL. There are two points for this sample: (1) this polymer has some helical content, and (2) the CD signal is insensitive to the formation of the oxide. The results in both Figures 5 and 6 indicate that the oxide forming in the presence of the polypeptide chain does not perturb secondary structure.

It is of interest to compare the current results to the work of Burkett and Read which studied how the folding behavior of 


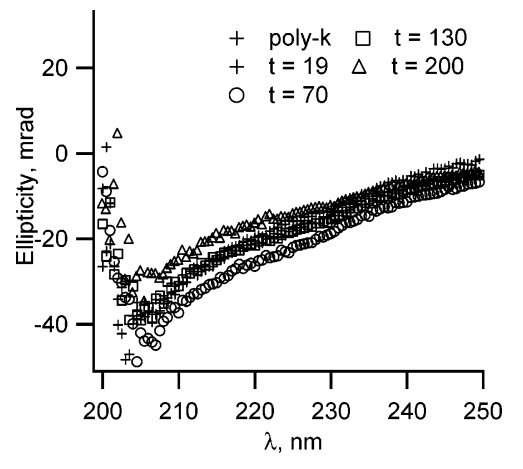

Figure 6. In situ circular dichroism data for silica made with 3800 MW PLL. The time denoted in the figure is in minutes.

short, alanine-rich peptides was modified by the presence of colloidal silica (Ludox). ${ }^{39,40}$ Their work shows quite clearly that these sequences lose some helicity due to electrostatic interactions between charged residues and colloidal silica with a surface charge. However, their CD results indicate the peptides still possess a helical structure, although helicity is decreased due to adsorption on the surface of the colloidal silica. Given the polydispersity, etc. of our system as compared to these short sequences, we cannot perform as rigorous of an analysis of the CD data as Burkett and Read. We did, however, perform CD measurements of PLL in the presence of $1 \mathrm{wt} \%$ Ludox HS-40 at $\mathrm{pH} 11.2$; in that case the PLL unfolded immediately upon addition of the Ludox. This is consistent with PLL not being as strong of a helix former as these short peptides. There are two major differences between their work and the current studies: 1) we are using a different silica source (TEOS), and 2) at the $\mathrm{pH}$ of our syntheses (11.2) the PLL side chains are not positively charged. Current work in our lab is exploring how PLL interacts with different colloidal silicates as a function of $\mathrm{pH}$.

One drawback of CD is that it is not possible to differentiate between PLL in solution, adsorbed on the surface of a silica particle, or occluded in the pores. However, our results show that the $\mathrm{CD}$ is essentially unchanged until long reaction times, at which time one would expect the overall signal observed to have decreased due to the presence of large scatterers in solution. This is strong evidence that the conformation of the PLL is preserved during silica formation. We believe that PLL which is occluded in the growing silica particles does not contribute to the CD signals observed in Figures 5 and 6, as CD on particles of as-synthesized AHTS that are resuspended in water do not show a CD signal.

Figure 7 shows the IR spectra of as-made AHTS. Numerous investigations have studied the correlation between the amide I and II bands of simple polypeptides, globular proteins, and secondary structure. ${ }^{41-45}$ We observe the amide I and II bands at 1653 and $1548 \mathrm{~cm}^{-1}$ respectively in as-made AHTS. The results for the AHTS sample are line with expected results for PLL in a helical conformation, however previous works have shown that the positions of the amide I and II are sensitive to many factors (e.g., $\mathrm{H}_{2} \mathrm{O}$ vs $\mathrm{D}_{2} \mathrm{O}$ ). ${ }^{41-45}$ With this in mind we

(39) Burkett, S. L.; Read, M. J. Langmuir 2001, 17, 5059-5065.

40) Read, M. J.; Burkett, S. L. J. Colloid Interface Sci. 2003, 261, 255-263.

(41) Blout, E. R.; Lenormant, H. Nature 1957, 179, 960-963.

(42) Blout, E. R.; Idelson, M. J. Am. Chem. Soc. 1958, 80, 4909-4913.

(43) Susi, H.; Timasheff, N.; Stevens, L. J. Biol. Chem. 1967, 242, 5460-5466.

(44) Byler, D. M.; Susi, H. Biopolymers 1986, 25, 469-487.

(45) Venyaminov, S. Y.; Kalnin, N. N. Biopolymers 1990, 30, 1259-1271.

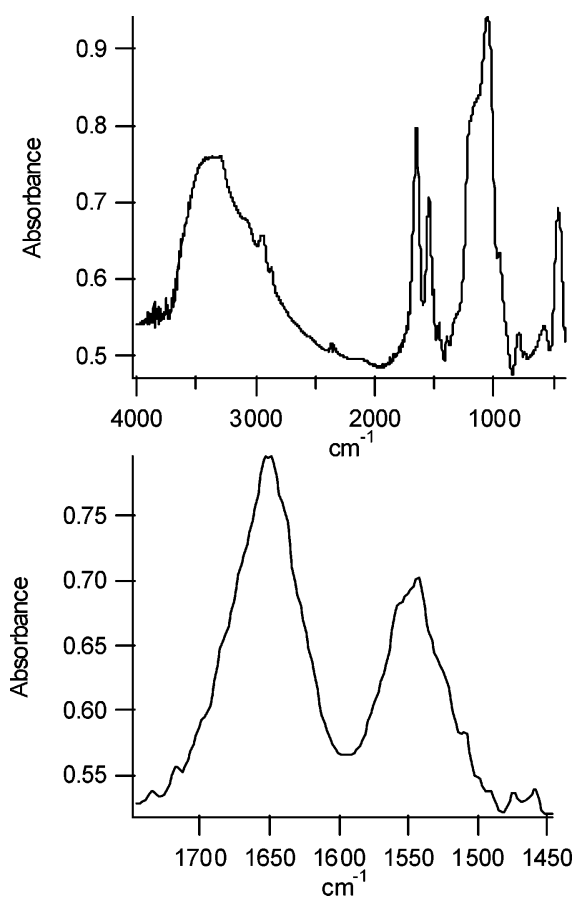

Figure 7. IR spectra of as-made AHTS (top) full spectrum, (bottom) expanded plot in the range from 1750 to $1450 \mathrm{~cm}^{-1}$.

believe recent studies by Müller and co-workers of oriented PLL films on polyelectrolyte coated silicon substrates are a useful comparison. ${ }^{46,47}$ For PLL in solution, they observe the amide I band at 1636 and $1647 \mathrm{~cm}^{-1}$ in $\mathrm{D}_{2} \mathrm{O}$ and $\mathrm{H}_{2} \mathrm{O}$ when PLL is a helical conformation; however, upon film drying they observe this band shifts to values slightly larger than $1650 \mathrm{~cm}^{-1}$ (spectra shown but results of fit not given). This latter value is in very good agreement with our results. Also the amide II band, which does not shift upon drying is at $1548 \mathrm{~cm}^{-1}$, in agreement with our results. Müller and co-workers report the amide bands are at 1648 and $1540 \mathrm{~cm}^{-1}$ in hydrated samples $\left(\mathrm{H}_{2} \mathrm{O}\right)$ for a random coil. The IR data of the silica made in the presence of 3800 MW PLL is shown in Figure 8 and is similar, though not identical to the results in Figure 7. There are two differences between the samples: 1) the amide I and amide II bands are broader in the low MW sample, and the peaks are shifter to lower wavenumbers by approximately $2 \mathrm{~cm}^{-1}$. We interpret the IR of the low MW sample as indicating the PLL has a more heterogeneous structure (hence broader bands) and possesses both small helical and random coil domains (hence small shift of bands). This result is consistent with the CD of the low MW PLL that indicates it possesses some helicity. The results of the fitting are summarized in Table 2 . We believe our IR results in conjunction with the in-situ $\mathrm{CD}$ measurements are strong evidence that the PLL retains its secondary structure both in solution during material formation and within the pores. These results are further evidence that the helical nature of PLL can be used to achieve a templating affect.

In a further attempt to understand the experimental adsorption data, we performed grand canonical Monte Carlo simulations of Ar adsorption data acquired of several AHTS samples at 77 K. Figure 9 shows an experimental argon adsorption isotherm as well as the adsorption branches of the isotherms generated

(46) Müller, M. Biomacromolecules 2001, 2, 262-269.

(47) Müller, M.; Kessler, B.; Lunkwitz, K. J. Phys. Chem. B 2003, 107, 81898197. 
Table 2. Infrared Spectroscopy Fitting Results

\begin{tabular}{|c|c|c|c|c|}
\hline & \multicolumn{2}{|c|}{$\mathrm{SiO}_{2}$ made $\mathrm{w} / 4 \mathrm{~K}$ PLL } & \multicolumn{2}{|c|}{$\mathrm{SiO}_{2}$ made $\mathrm{w} / 20 \mathrm{~K} \mathrm{PLL}$} \\
\hline & amide I & amide II & amide I & amide II \\
\hline peak position & $1650.5 \pm 0.2$ & $1546.1 \pm 0.3$ & $1652.4 \pm 0.2$ & $1547.9 \pm 0.3$ \\
\hline width & $39.2 \pm 0.4$ & $34.4 \pm 0.5$ & $35.4 \pm 0.4$ & $31.0 \pm 0.6$ \\
\hline amplitude & $0.173 \pm 0.001$ & $0.108 \pm 0.001$ & $0.250 \pm 0.003$ & $0.162 \pm 0.003$ \\
\hline
\end{tabular}
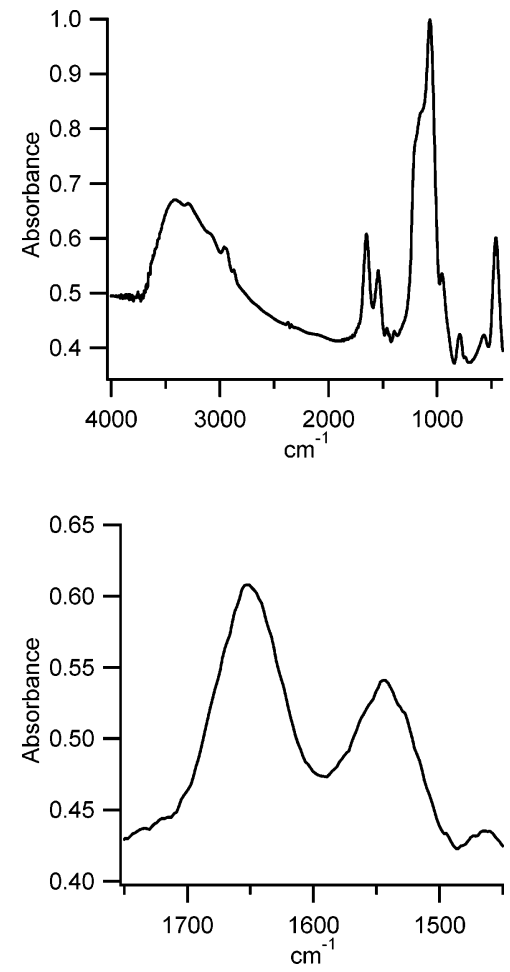

Figure 8. IR spectra of silica made with 3800 MW PLL (top) full spectrum, (bottom) expanded plot in the range from 1750 to $1450 \mathrm{~cm}^{-1}$.

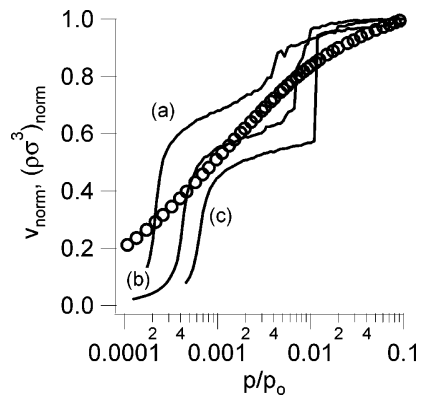

Figure 9. Experimental Argon adsorption isotherm (open circles) along with results from GCMC simulations of cylindrical pores 1.3 (a), 1.5 (b), and 1.7 (c) $\mathrm{nm}$ in diameter. Experiments and simulations performed at 77 $\mathrm{K}$. Isotherms are normalized to the volume adsorbed (experimental) and fluid density in the pore (simulations) at $p / p_{\mathrm{o}}=0.1$.

from the GCMC simulations for pore diameters of 1.3, 1.5, and $1.7 \mathrm{~nm}$. As can be seen the experimental isotherm lies between the three isotherms, consistent with the initial interpretation that the pores are cylindrical and approximately $1.5 \mathrm{~nm}$ in diameter. The isotherms shown in Figures 9 and 10 are normalized to the fluid density in the pore (simulations) or the volume adsorbed (experimental isotherms) at a $p / p_{\mathrm{o}}=0.1$. This is the relative pressure at which micropore filling is taken to be complete. We chose to compare the isotherms in this manner versus converting the simulated isotherms to other units (e.g., mmol/ $\mathrm{m}^{2}$ surface area) given the assumptions that need to be made to perform this conversion (for instance see discussion in ref 48).

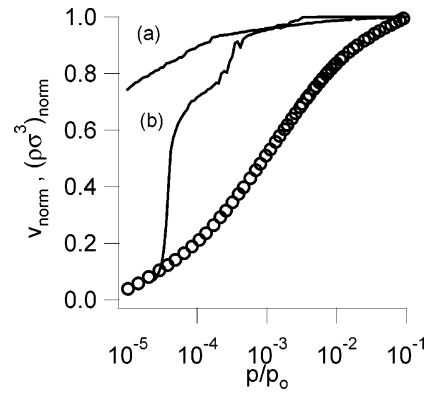

Figure 10. Experimental Argon adsorption isotherm (open circles) along with results from GCMC simulations of cylindrical pores 0.8 . (a), and 1.0 $\mathrm{nm}$ in diameter. Experiments and simulations performed at $77 \mathrm{~K}$. Isotherms are normalized to the volume adsorbed (experimental) and fluid density in the pore (simulations) at $p / p_{\mathrm{o}}=0.1$.

It is worth noting that the simulations consistently underpredict the amount adsorbed at low pressures $\left(p / p_{0} \leq 10^{-4}\right)$; this has been observed previously by Maddox and co-workers investigating adsorption on MCM-41 and their work shows this is a result of assuming the silica surface is energetically homogeneous. ${ }^{48}$ We make this assumption in the GCMC simulations performed here, and it is likely in error due to the presence of silanols, etc. The experimentally measured argon adsorption isotherms do not show any hysteresis, whereas hysteresis is observed in the GCMC results for pores above $1.6 \mathrm{~nm}$ in diameter. That we do not see hysteresis could be due to either (i) there are no pores present larger than $1.6 \mathrm{~nm}$, or (ii) the pore size polydispersity precludes its observation in the experimental data. Another point of note is that the experimental isotherms appear much smoother than the simulated ones; note that for instance at a pore diameter of $1.7 \mathrm{~nm}$ the GCMC results display a sharp step in the adsorption isotherm. Even highly ordered materials such as zeolites rarely exhibit such sharp features in adsorption isotherms. For instance VPI-5, a crystalline aluminophosphate possessing $1.2 \mathrm{~nm}$ diameter pores does not exhibit such sharp features in Ar adsorption isotherms. ${ }^{30,38}$ In the current case, we hypothesize that two issues prevent us from seeing such sharp steps in our adsorption data: (i) pore size polydispersity, and (ii) surface inhomogeneities. Both of these issues should decrease the uniformity of the surface, thereby leading to a distribution of energetics between the adsorbate and the silica surface. This will lead to a smoothing of the isotherms. Figure 10 shows the isotherms generated from GCMC simulations for pore diameters of 1.0 and $0.8 \mathrm{~nm}$ along with the experimental data for comparison. These are pore diameters one might expect from PLL in a random coil conformation. As can be seen these isotherms are not even qualitatively in agreement with what is observed; in these cases the pores fill with argon at $p / p_{\mathrm{o}}$ values of approximately $10^{-5}$ $(0.8 \mathrm{~nm})$ and $10^{-4}(1.0 \mathrm{~nm})$. We believe the GCMC results are consistent with our interpretation of the experimental results

(48) Maddox, M. W.; Olivier, J. P.; Gubbins, K. E. Langmuir 1997, 13, 17371745 . 
given above, and demonstrate the possibility for molecular simulations to aid experimentalists in interpreting data of new porous materials. For completeness we have included in the Supporting Information the Horvath Kawazoe analysis of $\mathrm{Ar}$ adsorption data of AHTS as well as the HK distributions of the isotherms obtained from the GCMC simulations. The HK analysis of the GCMC data points out the underlying shortcomings of using $\mathrm{HK}$ analysis for large pore ( $>1 \mathrm{~nm}$ ) microporous materials as it predicts two maxima which are moreover not at the expected values. This could be due to a variety of phenomena (e.g., monolayer adsorption in large micropores causing the first maximum) ${ }^{30}$ With this in mind we believe the comparison of the isotherms is most meaningful.

\section{Conclusions}

Here, using a simple polypeptide, poly-L-lysine, we show that secondary structure can be used to rationally design the porosity of silica made in its presence. Our work shows that silicas made using PLL in an $\alpha$-helix possess pores approximately $1.5 \mathrm{~nm}$ in diameter. This is consistent with small-angle X-ray scattering measurements that show helical PLL in solution to be cylindrical with a diameter of approximately $1.5 \mathrm{~nm}$. By contrast silicas synthesized with PLL in a $\beta$-sheet conformation possess larger pores, the size of which are a function of the PLL concentration, or in other words the size of the aggregate. In both cases highly porous materials are obtained $\left(>0.2 \mathrm{~cm}^{3} / \mathrm{g}\right)$. In-situ circular dichroism measurements of the synthesis mixtures show that the PLL secondary structure is not perturbed during synthesis in solution, and IR spectroscopy of as-synthesized AHTS is consistent with the $\mathrm{CD}$ results and supports the conclusion the PLL is in a helical conformation inside the silica. The results of grand canonical Monte Carlo simulations show experimentally measured isotherms are consistent with simulated isotherms of cylindrical pores between 1.3 and $1.7 \mathrm{~nm}$ in size, in good agreement with expected values. This approach is unique in that while many synthetic schemes utilize hydrogen-bonding interactions to direct the assembly of a porous oxide, here we use an isolated macromolecular structure versus an aggregate of molecules such as surfactant micelles. Our results suggest a new avenue for synthesizing porous oxides with highly tunable pore sizes and shapes under mild conditions and are proof of concept that the secondary structure of a polypeptide chain can be used to rationally manipulate the porosity of silica.

Acknowledgment. K.M.H. acknowledges the Engineering Academic Programs Office at Texas A\&M for a summer research fellowship. K. M. H. and D. F. S. also acknowledge the Texas Advanced Research Program for financial support. The SAXS instrument was purchased from funds obtained under NSF grant CTS-0215838. The authors acknowledge the Microscopy and Imaging Center (MIC) at Texas A\&M for access to the FE-SEM and TEM instrumentation. The authors also thank T. Good and J. M. Scholtz for useful discussions, J. Schmittschmitt for discussions about the CD experiments, $\mathrm{H}$. Cheng for acquiring SAXS data on the PLL solutions, and Texas A\&M University for financial support.

Supporting Information Available: SAXS measurements of poly-L-lysine solutions. $\alpha_{\mathrm{s}}$-plots of silicas made using poly-Llysine in an $\alpha$-helix and $\beta$-sheet conformation. Adsorption isotherms and $\alpha_{\mathrm{s}}$-plots of BSTS made with a low PLL content. $\mathrm{N}_{2}$ adsorption isotherms, $\alpha_{\mathrm{s}}$-plots, and XRD of silica made using $0.5,20$, and $40 \mathrm{mg} / \mathrm{mL}$ poly-L-lysine $\cdot \mathrm{HBr}$ in an $\alpha$-helix conformation. Horvath Kawazoe analysis of Ar adsorption data of AHTS and the isotherms from the GCMC simulations, and TEM of AHTS. This material is available free of charge via the Internet at http://pubs.acs.org.

JA049936O 